\title{
Re: Initial Complete Laparoendoscopic Single-Site Surgery Robotic Assisted Radical Prostatectomy(LESS-RARP)
}

To the Editor,

Laparoendoscopic single-site surgery (NOTES-LESS) has been gaining momentum in minimally access urological surgery. The incorporation of the robotic interface into the NOTES-LESS arena, proposes a symbiosis with promising future; Haber et al. (1), presented their experience with experimental with NOTES and robot in pigs for nephrectomies and pyeloplasties. Their results were encouraging in terms of feasibility. More recently, Desai et al. (2) presented an interesting work of transvesical radical prostatectomy (RP) in a cadaver model. Our group has previously report on a transitional experience to LESS-RP including both cadaver experimental and clinical experiences (3).

Previous detailed explanation and consent of the procedure, we have performed LESS-RARP in a 69 years old patient with prostatic cancer T1c. Patient's PSA and Gleason score were $8.50 \mathrm{ng} / \mathrm{mL}$ and $3+3$, respectively. Patient was fully continent preoperatively and reported active sexual life. Operation was performed with daVinci ${ }^{\circledR}$ interface and standard trocars (Figure-1). Ports were placed in a rhomboid fashion with the endoscope in the upper corner $(12 \mathrm{~mm})$, a $5 \mathrm{~mm}$ trocar in the lower corner for suction and traction purposes and $8 \mathrm{~mm}$ working ports at either side, without need of any other instrument. Clashing between instruments was verified externally and this hardened assistant's performance. Total operative time was $210 \mathrm{~min}$. Dorsal venous control was accomplished in $3 \mathrm{~min}$. with one figure of eight stitch. Urethrovesical anastomosis was performed in $35 \mathrm{~min}$. by separate stitches. An antegrade interfascial bilateral neurovascular bundle dissection was performed. Bipolar energy and metallic clips were used for hemostasis. Blood loss was $300 \mathrm{cc}$ and final pathology reported a surgical specimen of $66 \mathrm{~g}$, Gleason score $3+4$ with negative surgical margins. No perioperative complications were observed.

$\mathrm{RP}$ has been previously assessed in NOTESLESS urological surgery. Desai et al. (2) presented an interesting work of transvesical RP in a cadaver model. The procedure was performed in two fresh male cadavers. They employed four laparoscopic transvesical trocars and single-port device for their first and second cases, respectively, using the daVinciS robot (Intuitive Surgical, Sunnyvale, CA, USA). Both operations were completed transvesically and robotically. There was no need for additional ports. Operative time for the multi-port procedure was $3 \mathrm{~h}$ and for the single-port procedure was $4.2 \mathrm{~h}$. External conflict with robotic interface was experienced as a technical difficulty with the single-port procedure.

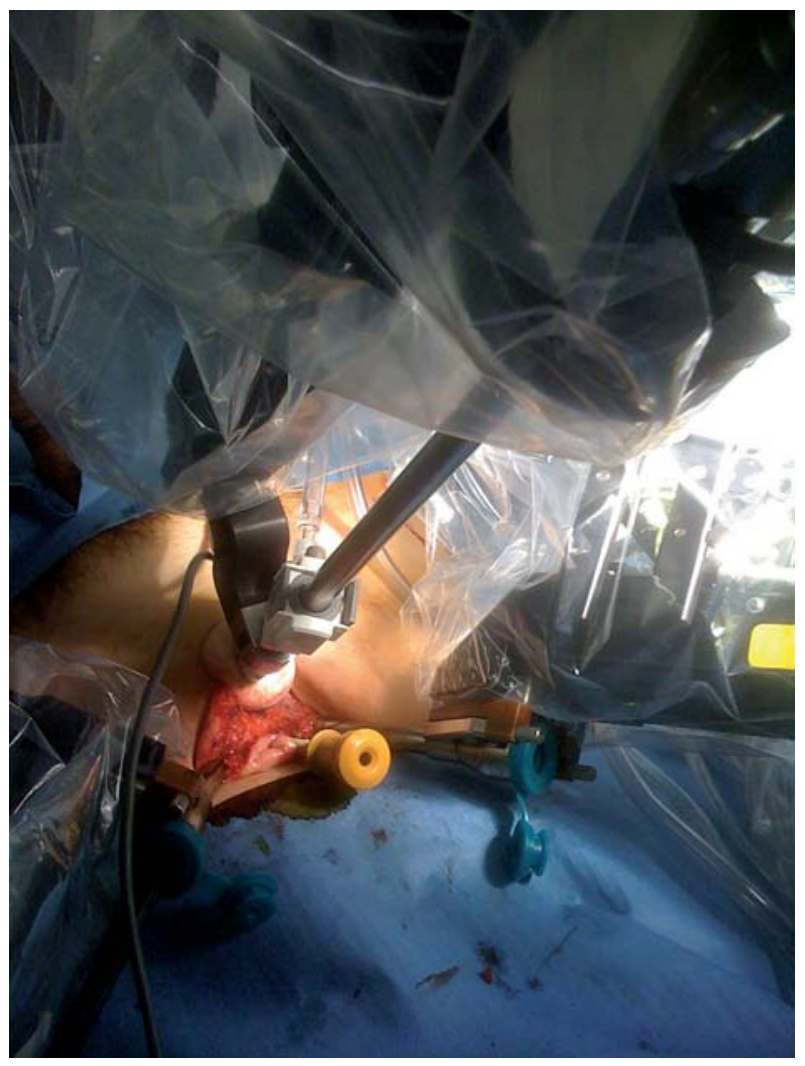

Figure 1 - Rhomboid trocar positioning for LESS robotic assisted. Dissection of aponeurosis allowed a separation of $3.5 \mathrm{~cm}$ between ports. 
In the clinical arena, Kaouk et al. (4) presented a series of single-port laparoscopic RP in 4 patients diagnosed with prostate cancer. They treated patients with localized disease, no previous pelvic surgery, and a body mass index $<35 \mathrm{~kg} / \mathrm{m} 2$. A single port device was placed transperitoneally through a $1.8-\mathrm{cm}$ incision located at the umbilicus without any other instruments or ports needed to complete operations. Urethrovesical anastomosis was performed using free-hand interrupted suturing and extracorporeal knot tying. This work is an impressive publication verifying feasibility of this procedure with the use of single port and articulated instruments. Kaouk et al have also presented a previous experience in LESSRARP using the R-port with adequate results.

We report to our the first clinical report of LESS-RARP. The procedure was successfully completed with the initial approach and a change in port triangulation was a key point to accomplish the task. Further evaluation of the technique is warranted.

\section{REFERENCES}

1. Haber GP, Crouzet S, Kamoi K, Berger A, Aron M, Goel R, et al.: Robotic NOTES (Natural Orifice Translumenal Endoscopic Surgery) in reconstructive urology: initial laboratory experience. Urology. 2008; 71: 996-1000.

2. Desai MM, Aron M, Berger A, Canes D, Stein R, Haber GP, et al.: Transvesical robotic radical prostatectomy. BJU Int. 2008; 102: 1666-9.

3. Barret E, Sanchez-Salas R, Kasraeian A, Benoist N, Ganatra A, Cathelineau X, et al.: A transition to laparoendoscopic single-site surgery (LESS) radical prostatectomy: human cadaver experimental and initial clinical experience. J Endourol. 2009; 2. [Epub ahead of print]

4. Kaouk JH, Goel RK, Haber GP, Crouzet S, Desai MM, Gill IS: Single-port laparoscopic radical prostatectomy. Urology. 2008; 72: 1190-3.

5. Kaouk JH, Goel R K, Haber GP, Crouzet S, Stein RJ. Robotic single-port transumbilical surgery in humans: initial report. BJU. 2008 Sep 3. Epub ahead of print.

Dr. Eric Barret, Dr. Rafael Sanchez-Salas, Dr. Xavier Cathelineau, Dr. Francois Rozet, Dr. Marc Galiano \& Dr. Guy Vallancien Department of Urology Institut Montsouris Université Paris Descartes Paris, France E-mail: eric.barret@imm.fr

\section{Re: The Influence of Statins on Prostate-Specific Antigen Levels}

To the Editor,

The influence of statin medications on prostate specific antigen levels is somehow controversial. Recently, Hamilton RJ et al. analyzed data of men who were prescribed a statin for a long-term period. The authors reported a statistically significant decline in PSA levels in men without prostate cancer, after they were treated with statins (1). This finding is in accordance with that of Cyrus-David et al., who also reported an important PSA decline in a small number of healthy men treated with statins for over 5 years (2). In contrast, Mills et al., who assessed the efficacy of statins in the treatment of lower urinary tract symptoms and prostate enlargement in a large, double-blind, placebo-controlled trial did not found 